\title{
Flow Visualization Studies in the Novacor Left Ventricular Assist System CRADA PC91-002, Final Report
}

\author{
Harvey S. Borovetz \\ Frank Shaffer \\ Richard Schaub \\ Laura Lund \\ John Woodard
}

no date

(Submitted January 1999)

\author{
U.S. Department of Energy \\ Federal Energy Technology Center \\ P.O. Box 10940 \\ 626 Cochrans Mill Road \\ Pittsburgh, PA 15236-0940 \\ and \\ University of Pittsburgh \\ 350 Thackery Hall \\ Pittsburgh, PA 15260-4020
}




\section{Disclaimer}

This report was prepared as an account of work sponsored by an agency of the United States Government. Neither the United States Government nor any agency thereof, nor any of their employees, makes any warranty, express or implied, or assumes any legal liability or responsibility for the accuracy, completeness, or usefulness of any information, apparatus, product, or process disclosed, or represents that its use would not infringe privately owned rights. Reference herein to any specific commercial product, process, or service by trade name, trademark, manufacturer, or otherwise does not necessarily constitute or imply its endorsement, recommendation, or favoring by the United States Government or any agency thereof. The views and opinions of authors expressed herein do not necessarily state or reflect those of the United States Government or any agency thereof. 


\section{DISCLAIMER}

Portions of this document may be illegible in electronic image products. Images are produced from the best available original document. 
Flow Visualization Studies in the Novacor Left Ventricular Assist System

Harvey S. Borovetz ${ }^{1}$, Frank Shaffer ${ }^{2}$, Richard Schaub ${ }^{1}$, Laura Lund ${ }^{1}$ and John Woodard ${ }^{3}$

\section{$\underline{\text { Abstract }}$}

This paper discusses a series of experiments to visualize and measure flow fields in the Novacor left ventricular assist system (LVAS). The experiments utilize a multiple exposure, optical imaging technique called fluorescent image tracking velocimetry (FITV) to track the motion of small, neutrally-buoyant particles in a flowing fluid.

\section{Introduction}

Since 1988, the Novacor LVAS (Portner et al, 1989) has sustained 27 cardiac transplant candidates at the University of Pittsburgh Presbyterian Hospital. Particularly impressive is the fact that of the patients who received a donor heart (18/27), all were discharged home well (Kormos et al, 1991). Nonetheless complex problems remain to be solved if the Novacor LVAS and other implantable blood pumps are to achieve widespread clinical use (Didisheim et al, 1989).

The motivation for this work is to further understand the dynamics of blood flow in the Novacor LVAS. In this project we use state-of-the art flow diagnostic tools to analyze flow fields around the pericardial valves of the Novacor LVAS.

${ }^{1}$ Department of Surgery, University of Pittsburgh, Pittsburgh, PA 15261

${ }^{2}$ U.S. Department of Energy, P.O. Box 10940, Pittsburgh, PA 15236

${ }^{3}$ Novacor Division, Baxter Healthcare Corp, 7799 Pardee Lane, Oakland CA 94261 


\section{FITV Methodology}

Fluid dynamic measurements are done with a technique called fluorescent image tracking velocimetry (FITV). FITV enables measurements to be made very close to biomaterial surfaces. Here a fluid is seeded with particles that follow the fluid flow - that is, neutrally-buoyant particles with low Stokes numbers and sizes much smaller than the length scales of the flow. A pulsed laser illuminates the seeded flow field at controlled intervals. The displacement of particles between laser pulses produces a velocity vector map of flow field. From this, other important parameters, such as shear stress and particle residence time, can be directly calculated.

FITV involves seeding the fluid with particles which fluoresce when excited with light of an appropriate wavelength. An important property of the fluorescent dye is its Stokes shift - the difference in excitation and emission wavelengths. Thus, the light from the seeded particles consists of both scattered light at the excitation wavelength, $\delta_{1}$, and fluoresced light at a different wavelength (mean fluorescent emission, $\delta_{2}$ ). Adjacent to solid boundaries in the Novacor LVAS, the light scattered by the flow boundary is at the same wavelength, $\delta_{1}$, as the excitation light. Almost always, the intensity of the light scattering by the solid boundary is much stronger than that from the seeded particles. The result is a low signal-tonoise $(S / N)$ ratio for particles near the flow boundary.

The $S / N$ ratio is increased dramatically by placing an excitation filter in front of the imaging camera. The excitation filter occludes the light scattered by the flow boundary at $\delta_{1}$ - the camera sees only the fluorescent light emitted by particles at $\delta_{2}$. This approach has provided excellent $S / N$ ratios of particles adjacent to the pericardial valves in the Novacor LVAS.

\section{Cardiac Simulation Flow Loop}

For this study it is essential to acquire the FITV data under realistic patient hemodynamic conditions. To this end, a cardiac simulation system is interfaced with the Novacor LVAS as shown in Figure 1. This allows simulation of the flow conditions (pump stroke volumes, frequencies, rate of filling and pump outputs) monitored in Novacor LVAS patients at the University of Pittsburgh.

A Novacor LVAS was manufactured from transparent materials to provide optical access for FITV. A transparent blood analog fluid is also used ( $42 \%$ by wt. aqueous spectrophotometric-grade glycerin). The blood analog fluid is seeded with "red" fluorescent particles manufactured by

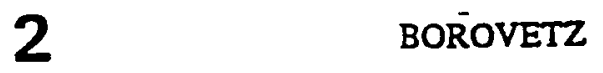


Duke Scientific Corporation (Duke Scientific Corporation, Palo Alto, CA). The particles are neutrally buoyant and their size is $30 \pm 2$ microns.

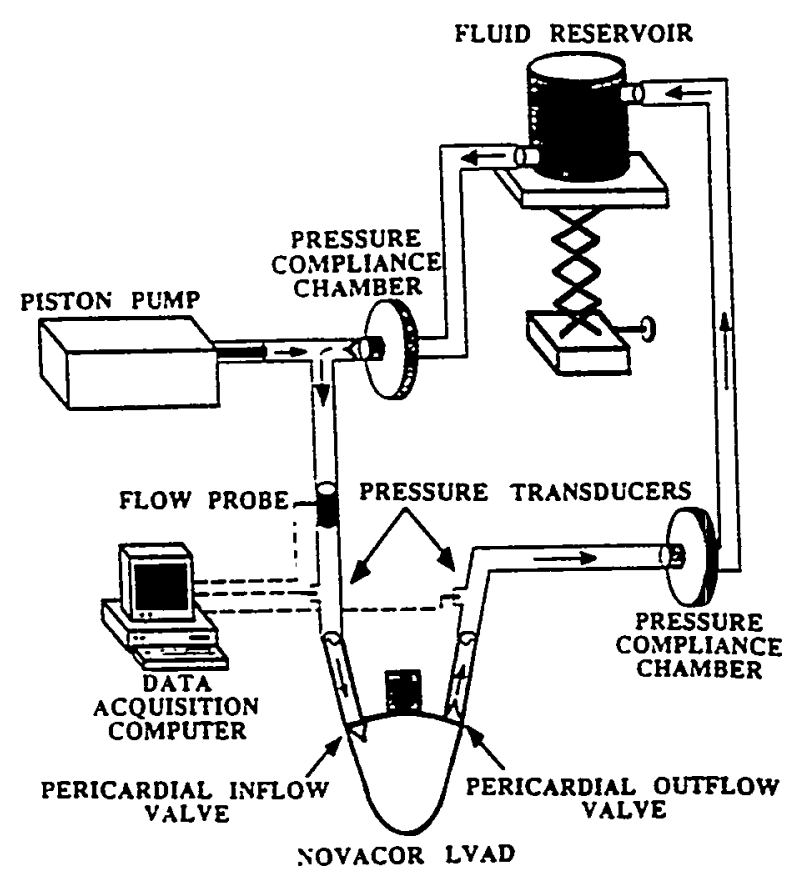

Figure 1. Cardiac simulation flow loop

$\underline{\text { Results and Discussion }}$

The flow conditions for FITV measurements simulate the full range of clinical conditions observed for cardiac transplant candidates at the University of Pittsburgh: pump rates extend between 60 to 120 beats/minute with fill volumes ranging from 25 to $60 \mathrm{cc}$.

Figures 2 displays a typical FITV image acquired at a pulse frequency of $222 \mathrm{~Hz}$. This image corresponds to the time in the pump cycle when the valve leaflets are stationary and the particle velocities adjacent to the pericardial valve are low. During the opening and closing phases of the valve leaflets, the velocities are elevated, suggesting an important contribution of the leaflet motion to "valve washing" and avoidance of areas of stasis.

By providing high resolution, quality images of the flow fields adjacent to the pump inflow and outflow valves (Figure 2), the present series of experiments yields new insight regarding Novacor LVAS fluid mechanics under realistic (clinical) conditions. For example, we have 
documented the marked variation of the flow fields adjacent to the pericardial valve as a function of time (systole, diastole, etc) during the LVAS pumping cycle. Preliminary quantitative analyses of these images, which were obtained for an LVAS pumping rate of 100 beats/minute, indicate that the flow speed near the valve surface can vary by a factor of 50 during the LVAS pump cycle. Other images (not shown) demonstrate conclusively that both the volume rate of pump filling (dV/dt) and LVAS stroke volume profoundly influence the flow fields around the inflow and outflow valves. Our ongoing FITV studies are aimed at further exploring these and other hemodynamic variables which may be relevant to the clinical management of Novacor LVAS recipients.

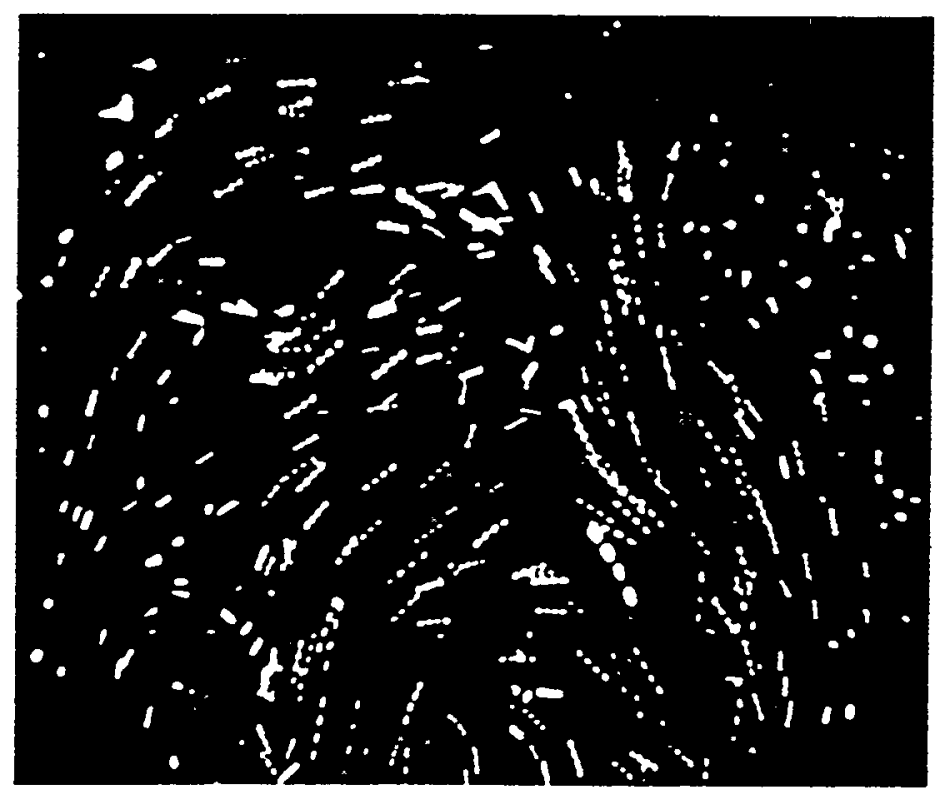

Figure 2. FITV derived flow pattern in the Novacor LVAS.

\section{$\underline{\text { References }}$}

Didisheim P, Olsen DB, Farrar DJ et al, "Infections and Thromboembolism with Implantable Cardiovascular Devices" Transactions of the American Society for Artificial Internal Organs 1989; Vol 35, pp. 54-70.

Kormos RL, Borovetz HS, Armitage JM et al, "Evolving Experience with Mechanical Circulatory Support" Annals of Surgery 1991; Vol 214, pp. 471477.

Portner PM, Oyer PE, Pennington DG et al, "Implantable Electrical Left Ventricular Systems: Bridge to Transplantation and to the Future" Annals of Thoracic Surgery 1989; Vol 47, pp. 142-150. 


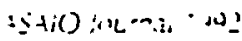 \\ SLIDE FORUM 10 \\ CIRCULATORY ASSIST/NEW DESIG.\S
}

\section{Development of an Axial Flow Blood Pump LVAS}

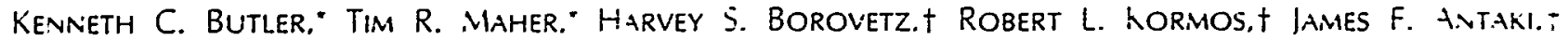 \\ marina Kameneva. $\dagger$ Bartley P. Griffith. $\dagger$ TONy Zerbe. $\dagger$ tvo Frank D. Schaffer $\ddagger$
}

Nimbus, Inc., (Rancho Cordova, CA) and the University of Pittsburgh (Pittsburgh, PA) are collaborating to develop an implantable rotary blood pump that can be used as a leit ventricular assist system (LVAS). The short-term goal of this project is to show that an LVAS based on this pump can operate safely and reliably during chronic implantations in animals. Work conducted to date includes in vitro testing of hydraulic performance, hemolysis, endurance demonstration, and flow visualization. Results indicate that the pump is capable of generating an output of up to $10 \mathrm{~L} / \mathrm{min}$ at physiologic pressures. Associated electrical power to drive these pumps is in the range of 6-10 watts. One integrated pump was placed in a mock ilow loop and operated continuously at a fixed speed $(10,000 \mathrm{rpm})$, pressure $(100 \mathrm{mmHg})$, and flow rate $(6 \mathrm{~L} / \mathrm{min})$ for 90 davs with no apparent difficulty. In vitro hemolysis test results have consistently ranged between 3-6 $\mathrm{g}$ of liberated hemoglobin/dav, which is an acceptable range for chronic use. Two in vivo trials of 7 and 14 days were periormed using calves, aiter which tests have been done using sheep as the animal model. Five short-term sheep experiments have been conducted with good results. Future studies will include implantations in sheep of 3 months duration. ASAIO Journal 1992; 38: M296-M300.

Practical considerations of mechanical circulatory support st stems that orter the potential ior chronic treatment of endstage heart disease raise issues that extend bevond merelv developing sale and eriective devices. Three issues in particular are relevant to the eriect of artificial heart technologv on this nation's health care svstem': I concern about the cost enectieness or a mechanicai curculator support sistem 'MCSS, that is, assuring that the aguregate increases in health care cost will be oriset br improved patient uut-

From "Vimbus, Inc.. Rano no Cinroova. Calitorna, the + L nuersitv ¿ Pittshurgh. Pittshurgh. Pennssiranid, and $=L=$. Department or Enerav. Piltsburgh Enerav and Terhnologer Center. Piltsburgh. Pennsvlvanid.

Reprint requests: Kenneth C. Butler. Jimnus :nc.. 20.45 Kilgore Rd Rancho Curdova, LA 45n.0. comes: 2" concern that MCSSs will be used approorlateiv. and 31 concern relative in accessibilitv to MCSSs, for evampie. assuring that there will be equitable patient access in these life-sawing therapies.

When these issues are translated to .MCSS siem iedtures. It is apparent that several essential design reauirements must be met.

First, an MCSS must possess the necessan ilow perrormance. phvsılogıc compatibilitv. durabilitu. and reliabilutv attributes currentlv expected of a chronic device. Second. VCSSs should be as small and simple as possible. be comoaraivelv easv to impiant and operate, and be anatomicails compatible with the bodv habitus of both men and women Finaliv. the cost of an MCSS should not be a barrier etther in its development as a commercial product or to its citnical uulization bv the medical communitv.

vimbus and its development partner, the Universin or Pittsburgh's School oi Medicine IUOPI, believe that meetung these criteria will require new devices in addition to exusung iechnology. Furthermore. the inherent small size and straightiorward mechanical design associated with contunuous flow pumps make these devices particulariv attractive as tuture .MCSSs. Consequentlv. Nimbus and the Universiti have embarked on a joint venture to develop an implantable feit ventricular assist svstem (LVAS) that uses an dxial flow rotary pump to generate cardiac output.

$\checkmark$ imbus created the iirst miniature axial how blood pump tor the Hemopump. a $21 \mathrm{Fr}$. temporarv LVAS that has undergone substantial clinical use in both the United States and Europe. "s titer developing the Hemopump. Nimbus began iniestigating a scaled-up version of the axial flow concept ior chronic ventricular support. ${ }^{5.6}$ The results of this invesisation torm the foundation for the project discussed below.

\section{Methods}

\section{$\therefore$ x/di Flow LliS Description}

The prototvpe tor a chronicallv impianted axial dow LV tS. designated the AX-LVAS. is comprised of three mator a!e. ments: 1 , the integrated pump/motor. 2) an inslow ano ustflow cannulae set. and 3) the external controller and oower 


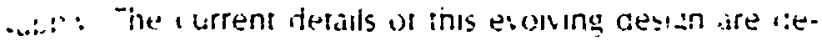
$\because$ : :ro vetisu.

Blood Pump. Figure 1 shous a priotograbn of the inteMel: motor/axial flow blood pumb. This unit. ankn :s iab-

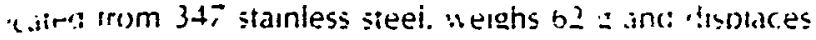

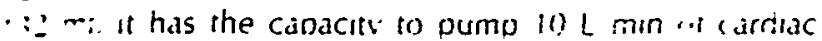

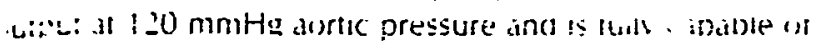

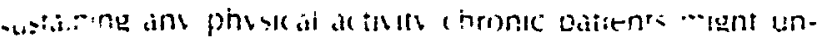
:rorisne figure 2 vilustrates how the bumb nter'it wa th "re "ulation through an intlow cannuld coren :"i:) "ne ter! entrocular apex and an outrlow cannula anasiommoed to the iscencing aorta.

The oump consists of a single axlai stoge rotur sinc matchine satior integrated into the center ot the cirme suotor. joural bearings support the rotating assembil rakakl. and a nudrostatic ace bearing prowdes a vad thrust balance and a blowd seal interiace. Two cables connect the imnuanted unit (1) an esternal controller. One cable contains the sfectrical wres carrung current to the motor. wheress tre vecond cable is a conduit that supplies a pressurizec onisiologic lluid to the interior of the pump tor the bearing ana blood seal !ubrication. Approxumatelv ij ml. dat of riudi is required (o) maintain seal patency $15^{\prime \prime} n$ mixture ol c:evtrose in inder:

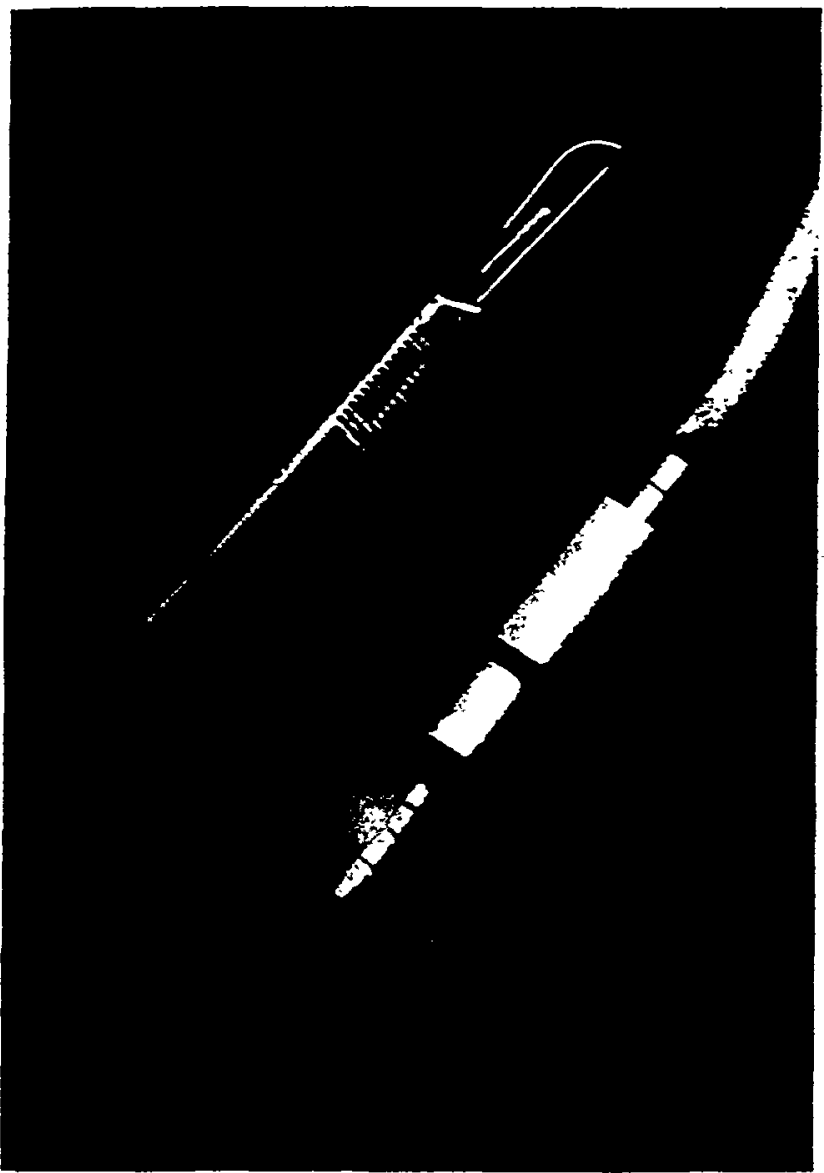

Figure 1. Implantable axial flow blood pump.

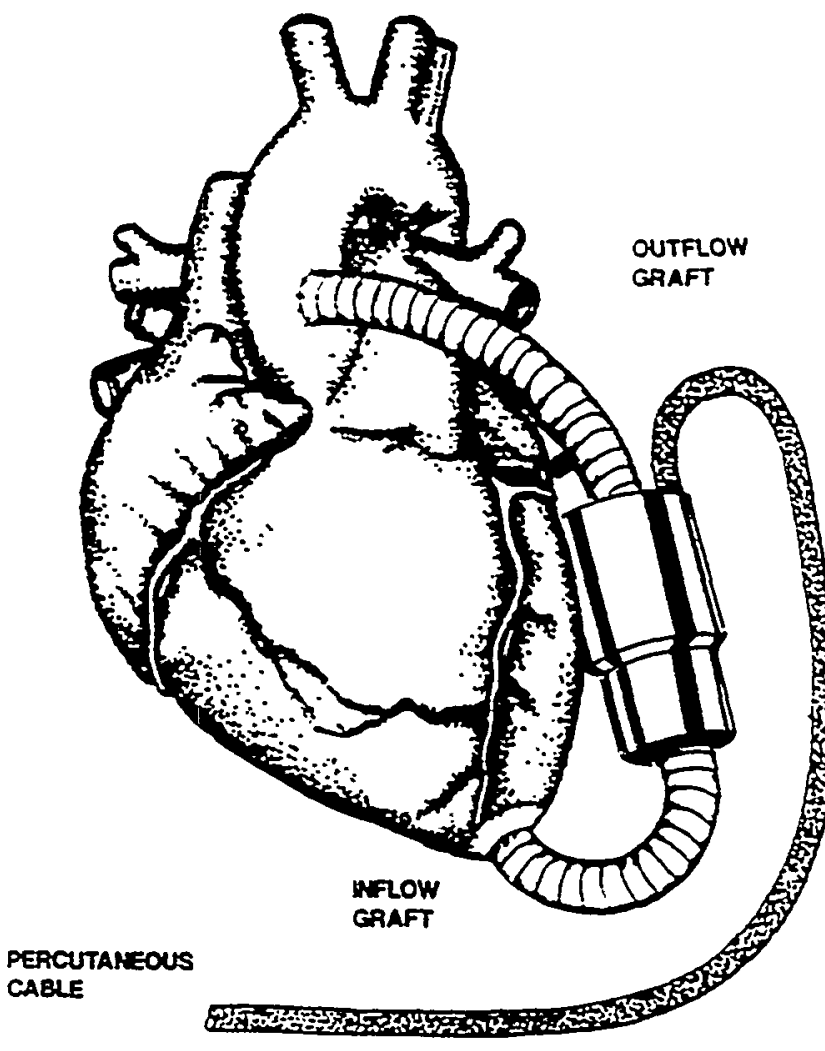

Figure 2. Axial flow left ventricular assist system anatomic place ment.

Inflow and Outflow Cannulae. Inilow and outriow cannuiae are coniigured ior the left ventricular apex to ascending uorta connection. The inilow cannula is dip-cast irom ment. cal grade silicone rubber, and is a smooth-wailed. :ire reiniorced conduit $110 \mathrm{~mm}$ i.d.. $=15 \mathrm{~cm}$ long). It is bonded to a stıri apical tube for penetration of the leit ventricle. and heat iormed to create the desired bend angle. The outriow carinula is a conventional expanded PTFE IGore-Tex: grant.

\section{External Controller}

The controller has three basic iunctions. First. :t provides primarv electrical power and the control signals inat energize the motor stator and varv the motor speed on riemand. Second, it provides the purge iluid supplv functions. Thırd. i: displavs diagnostic iniormation: electrical power. motor speed, and purge pressure.

\section{Fiow Visualization Tests}

Flow visualization techniques are being used to reme the low geometrv within the pump and inilow cannuta. Alaserbased partıcle trackıng technique, termed iluorescent image trackıng velocımetrv IFITV'. is being used to track ine mortun oi neutrallv buovant. $30 \mu \mathrm{m}$ diameter particles winn the tow field. ${ }^{3}$ An argon laser illuminates the seeded :ow lleln wh subsequent image processing providing :ame-buirame particle locations: summation oi such :uccessivr 
ram Mi:s is usd, which nas the pumo ndraulic elements mouried in a transparent housing, driven bv a ilevible cable. the sump circulates a blood iluid anaiog contanıng the par: ure 3 i a schematic illustration ot the troerimentai set-up.

\section{$\because$. I Experment:}

nital in (16) stuates of the $+1-11$ ts condicied by VImas consisted ol (wo implantations in :aises. one ol - dats ind one of 14 dals duratıon. The anımai model currenth used is the adult sheep. Thus rar. sheed implantations have consisted or a series of short-term $1 \leq 1$ weekl studies. These iests are intended to 11 opumize the design ot the blood pumb and cannulae. 2) demonstrate hemodinamic capabılivi if the implantable svstems. and 31 cnaracterize the interiace reaction between the $A X-L V+S$ and the host anatomv and vissiologv.

The pump is implanted through a sternotomv procedure. The sinlow cannula is connected through in apical core made in the ventricle. The outtlow grait is anastomosed in an end-to-side ashion to the aorta. After priming. pump operation is begun, and the implantation site is closed. titer the inimal recovers irom anesthesia. it is placed in a specially designed stall. and thereatter is attenced continuously by medicat and veterinarv stari. Routıne monıtorıne inciudes an irras ot parameters tor hematologic. biociemical. hemodvnamic. and pump operating status.

Results

in Virn Tests

Flow Periormance. Pumps were tesied in tiro oser a ange if rotatıng speeds and specined uderatung pressures. blumetric llow rate was measured at each test conation. inereo: generating a tlow map. Figure $\$$ displavs one such map ior the latest pump blade coniguration using boune blowd as the llow medium at pressures that ranged from the

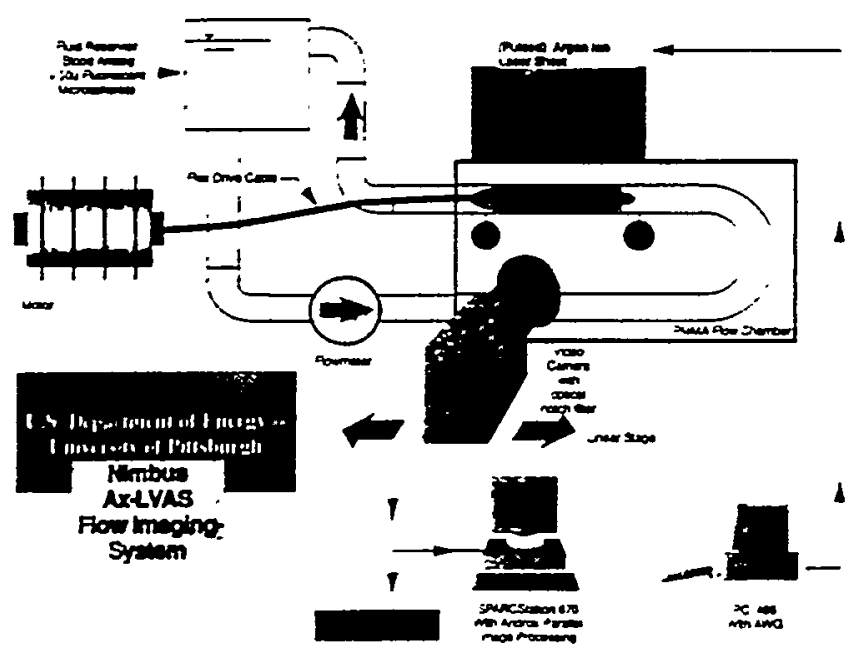

Figure 3. Flow visualization test scnematıc.
PRESSURE RISE (mmHg)

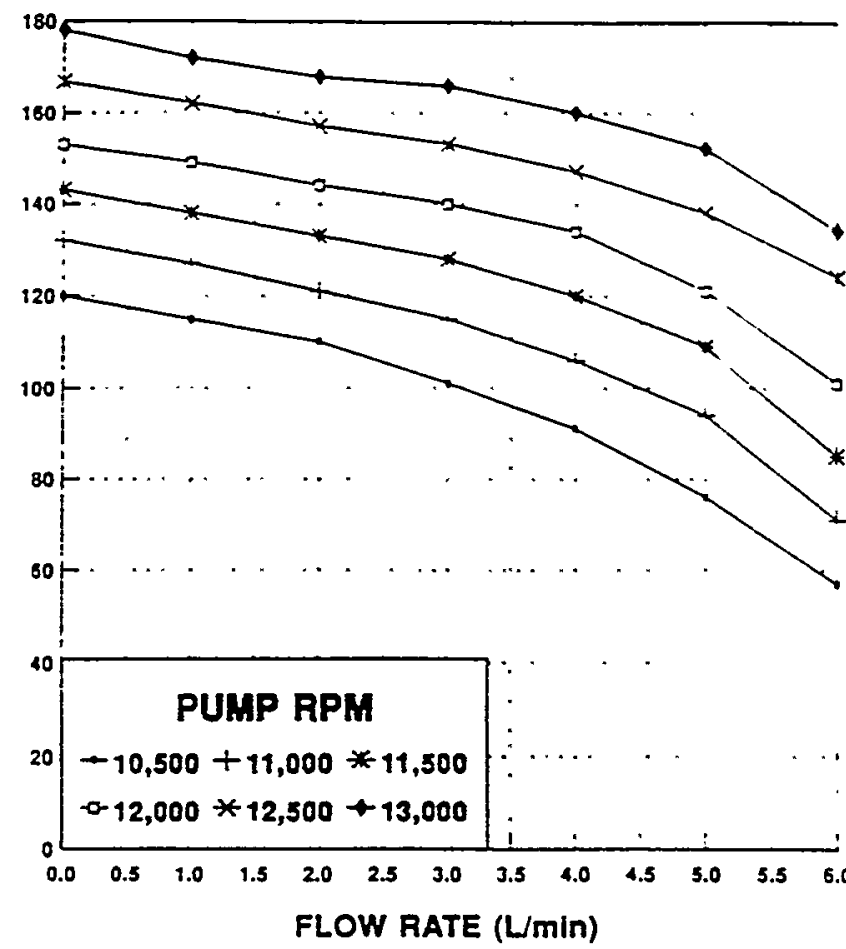

Figure 4. $\mathrm{H}-\mathrm{Q}$ performance integrated pump $\mathrm{S} / \mathrm{N} 003$ in bovine blood.

Ilow $220 \mathrm{mmHg}$ (shut-oif condition) to $40 \mathrm{mmHg}$ at the low end.

Hemolysis. Various blade coniigurations were tested ior hemolısıs generatıon using bovine blood. The amount of tree hemoglobin liberated within a known volume or cırcu. lating blood is determined for specified intervals. The result is expressed as an average hemolvsis index in grams per dav. Results ior one continuous test of the latest blade design are listed in Table 1. For reierence, the Hemopump's bench mark level is $+\mathrm{g} /$ dav. A value lower than $10 \mathrm{~g} / \mathrm{dav}$ is the generallv accepted level for device related hemolvsis (Table 1).

Endurance Demonstration. An integrated pumo was placed in a flow loop contaınıng normal saline and operated contınuouslv at a rixed speed and pressure $16 \mathrm{~L} / \mathrm{min} .100$ $\mathrm{mmHg}$ ) ior 91 davs, the intended duration. Purge flow rate was mantained at an average value of $20 \mathrm{ml} / \mathrm{day}$. Durıng the test. the pump's operatıng parameters stayed withın normal ranges.

Table 1. Axial Blood Pump in Vitro Hemolysis Test Results

Pressure (mmHg) Flow (L/min) Speed (rom) Hemolysıs (gm/day)

\begin{tabular}{llll}
\hline 100 & 5.0 & 11.000 & 40 \\
120 & 5.0 & 12.000 & 40 \\
140 & 5.0 & 13.600 & 59 \\
100 & 7.0 & 12.000 & 35 \\
\hline
\end{tabular}


:uif-i-a uspectuon of the pump iomponents snowed m.il the searing and jeal surraces eyperienced wriah no itur and :nus were capable oi much longer pertusion times. -i.e moint intucant tinding was the presence of corrosicon "1) -i,ilnie-s steel components m stumc contact with the sawhe shic 7 is caused bv crevice corrosion mechanisms anis - in ir: , ipated result of hong-term ronsure of sianits:

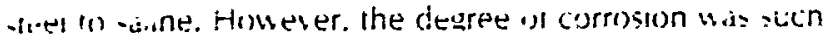
"rull ihe :ump could have run consicierabil ionger belure - iruc turai segradiation would have arecird bump operation. This problem is being corrected bi siltching trom the $3 i$; -ianless sizel used in previous pumps $(1)$ a 0 HL-Al illanicm silou.

Flow Visualization. These dre on-gonng tests. and results ire preliminarv. The ilow field has been mapperi at discrete ivations with the inilow cannula, at the entrance to the ortor. between adjacent rotor blades. at the rotor exil-stator mintrance section. and at the stator exat. Examination of the liom streamine patterns suggests that the blade angles ar propers urrented, and that no signiticant areas of recircula(ii)n or sevaration develop during normal operation of the pump. Tirere does appear to be a relativel hign veioculs impact area in the pump's inducer section. and this is being stucied iurther.

In bivo i:

Implantation Duration. Five sheep have been implanted wh the 4 Y-LVAS. Implantation times ranged irnm 12 to:-2 hr. All cases were electivelv termınated. and the sneed were in no apparent discomiont at the ume thev were suled. vo ievice related problems occurred.

Hematologic, Hemodynamic, and Biochemical Evaluation. titer the initial postoperatwe period. pump speeds $\therefore$ mannalned between 10,000 and $12,000 \mathrm{rpm}$. Pumo - utputs exceeded 6 L.min. Leit ventricular decompression was verited by usual inspection bejore chest closure and - herearter bo measurement of lett atral pressure. t dimin. ined pulse pressure was routinelv observed in these animals ie 9 . 1 rom $\geq 30 \mathrm{mmHg}$ pre-implantation to $10-20$ ' $\mathrm{mmHg}$ at $\cdot \mathrm{mm} \geq 10.000)$. Arterial blood gases $\left(\mathrm{pH}\right.$. $\mathrm{pO} \mathrm{O}_{3}$. and "CO:! generallv remaned within normal limits. Consistent with the - : itro rindings. the electricai power required by :he sivtem (1) generate this pertormance ranged between ind 10 walts.

Eiectroute concentrations. creatınıne. BL' $\checkmark$. total protem. ind liser enzumes all remaned at baseline ipre-ımplantauon nurms. Table 2 detalls the plasma iree hemogiobin lev-

Table 2. Axial Blood Pump In Vivo Hemolysis Test Results

\begin{tabular}{ccc}
\hline Implant Time & Speed (rpm) & Plasma Hemogiodin (mg/dl) \\
\hline Baseine & - & 2.0 \\
1 nour & 11.200 & $\$ 5$ \\
8 hours & 10.100 & +5 \\
12 hours & 10.100 & 70 \\
24 hours & 11.200 & 270 \\
48 hours & 11.400 & 275 \\
72 hours & 11.400 & 13.5 \\
\hline
\end{tabular}

-15 as a iuncilon al tume anci vumo speed in one recent experiment. t slignt rise in hemolisis at $2+\mathrm{hr}$ was toiluwed bo a return toward baselıne bi 3 davs arter implantation Other noices of bilord rheologe. including asvmptotic witimate Ventoriani bloud iscostr. olasma viscosith. and eringr-

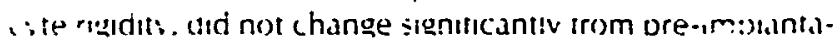
:an balues. therage values tor hematocrit ranged $1 \% \mathrm{~m}$ :'", (0) 2-"." (Table 2).

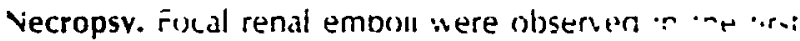

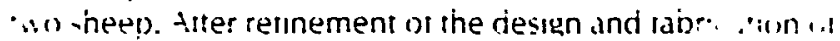
the annulae. no renal or puimonarv emboli wre aloce. mented. In several of the animals. examination or the carriar - hambers indicated ischemic injurv near the insermon site of the inslow cannula. suggestue of decompression ot ne int :entricle around the cannulation site. Lung atelecinisls was documented in one anımal. to remarkable inain:zs itere noted ior the liver or other organs. There has been no indic aion of tissue damage due to excessive device intericice 'em. p)eralures.

The pump liow passages have been round to be ganprail iree or cellular debris. Microscopic deposits of ded been noted at interiace discontinuities along the blood $\$+31$ and along the outer edges of the stator blades. born or $\mathrm{W}$ in $\mathrm{h}$ ire normal indings. Predictablv, there has been no irace of blood elements behind the seal.

\section{Conclusions}

Our results to date with the AX-LVAS support the isserion that this device can meet the essential requirements or a chronic MCSS. Compared with existing pulsatıle devices is small size and simple nature address the need or ease of implantation and applicability to a broad patient popuatıon. These ieatures also mean signiricantly lower costs. sot onit 10) the clinical product but for the program that wili be reyuired to obtain Food and Drug Administration approval of this Class III device. In addition. these ieatures will low er the risk oi development and qualiticatıon, which will atso decrease costs.

Test results of integrated blood pump/motor units indicated that the liuid supported bearings and seai orier the potential for an exceedinglv long operation lite tor the nump. In addition. the basic biocompatibilitv or the $t . X$ iv 15 has been veritied bv both in vitro and in vivo resuits. To be sure. iurther in vivo testing and in vitro reliabilit testıng tie ahead to prove the capabilities of the $A X-L V+S$ conciuslleiv.

The kev to the life potential of the AX-LVAS is use of the active purge liuid to lubricate the seal and bearıngs. Obuouslv, this approach complicates the design and use of this pump compared with one that does not require an external lubricating iluid. However, the Nimbus/UOP researcn team urmlv believes that this complication can be addressed in the clinical setting, as well as in everv dav life situations or chronic patients. An important basis for this belief is the experience of the UOP team in the care of MCSS paitients in non-hospital settings."

The major reason to eliminate the purge requirement is that it is not compatible with a totally implanted .MC $\mathrm{M}$. We. 
and ritrers. are working on concepts inat ro not require iubricat inn with external iluid. However, these conceots are in the cart development stage, and ail are iaced with a long und rish. development course. This iact is illustrated by the dilemma associated with blond lubricated bearings. ior ahich ir a univ wav to veritv endtrance capadiltv is inrough long-term testing in coagulable bluod: a .r. dinclut and isil c- aertakıng. In the :ong-term. Imblanten rotan sump it tis it it do not require percutaneous inne: $w$ il surelt be lustirted. $n$ addituon $m$ the blood pump. inese st stems wil require in implanted internai batterv. a transcutaneous entrgı transmission svstem and its implanted coll. and an implanted 7iniature electronic controller. Signiticantiv more complicäted svstems are involved. ds are more extensive surgen and increased cost tactors. Indeed. these complicaions reoresent a departure irom our viston or what an ideal. midelv used device shouid be.

in one sense, the percutaneous $4 X-L V+5$ can ise biewed as an interm device, a necessarv and improriant siep toward (iteselonment of totalk implanted blosd pumb sistems irased on continuous ilow technologi. On the osiner hand, it malv also oe enturelv suitable for some chronic pattents. ior whom the higher rishs associated with perculoneous access mav be otset bv the lower cost and ease ot imnlantation of the simo:er sustem. The motuation ror development oi purge-tess pumps will evolve as ive move lamaras totall implantagte LVASs. Neanwhile. there is much io be gained with this tr-LVAS approach. both in terms or ootental clinial trals $=$ and the knouledge to be dermed arom the cinical bise al comtinurus low devices.

\section{Reierences}

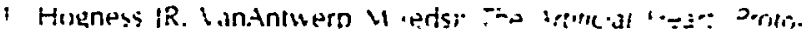

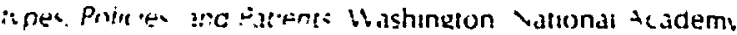
Press iaci

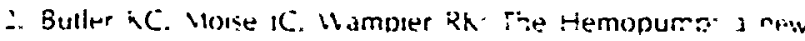

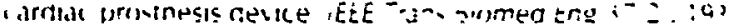
1'ih. 160011

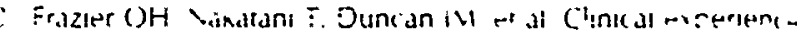

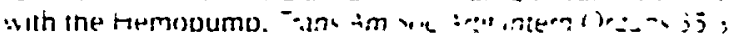
6) () 4 -buh. 1089

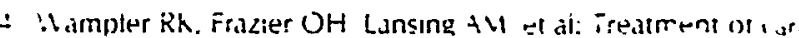
(ilogenic shock with the hemopump iell ventricular josist do. be. Inn inorac Surg 52: 506-513.1991

3. Butler KC. Wampler RK. Waher TR. el al: Demonstraiwon ann evaluatisn or an impiantable a vial tlow slood pump --nceeco.

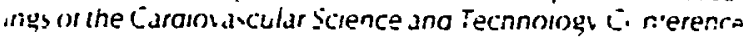
11WII. Bethesda. Varvland. 1991 o. 183.

i). Butler KC. Wampler Rk. Grinith BP et ai: Development of in implantable dxial rlow LV.AS. Proceeangs or the internatioral

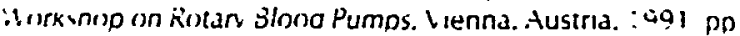
148.153.

- Scharier F. Ekmann I: Development or pulsed laser ı pus imetr sistems utilizıng photoelectrıc image sensors tmeric $3 n$.nvi. iute ot teronautics ana tstronautics: : i fitua Dinjork 6 , ir. yress. Cincinnatı. OH. 1988. pp. 194-1953

8. Schaïer $F$. Mathur $M$. Woodard I. et al. Fluorescent image irackıng velocımetry applied to the vovacor ielt ventricular assist device. Proceedings oi the tmerican jocletv or Hecnan. "ail Engineers Fluids Engineering C.mierence. Los tngeles C.A. June 1992.

4. Kormos RL. Borovetz HS. Winowich S. Armitage IM. Grinith BP. Out-ut-hospital facilitv tor the vovacor bridge to transpiant pattent: the Pittsburgh Familv House Experience. - oviras: 15.4/() 20:13.1991. 


\title{
FLUORESCENT IMAGE TRACKING VELOCIMETRY APPLIED TO THE NOVACOR LEFT VENTRICULAR ASSIST DEVICE
}

\author{
F. Shaffer and $M$. Mathur \\ U.S. Department of Energy \\ Pittsburgh Energy Technology Center \\ P.O. Box 10940, Pittsburgh, PA 15236 \\ J. Woodard
Baxter Healthcare, Novacor Division
7799 Pardee Lane, Oakland, CA 94261.
}
H. Borovetz, R. Schaub, J. Antaki, R. Kormos and B. Griffith
University of Pittsburgh, Department of Surgery
Pittsburgh, PA 15260

\author{
R. Srinivasan and R. Singh \\ Science Applications International Corporation \\ P.O. Box 10940, Pittsburgh, PA 15236
C. McCreary
Gilbert Commonwealth
P.O. Box 10940, Pittsburgh, PA 15236

\begin{abstract}
This paper discusses a technique, and the associated experimental equipment, to visualize and measure flow fields near biomaterial surfaces. The technique is called fluorescent image tracking velocimetry (FITV). It is a multiple exposure, optical imaging technique to track the motion of small, neutrally-buoyant particles in a fluid flow field. The particles may be small enough to follow the fluid flow and to approach the size of actual blood cells (1-10 microns).

The main advantage of FITV is the ability to measure the motion of small particles close to - even touching - a biomaterial surface. The motivation for this study is to achieve mappings of flow fields close to biomaterial surfaces in a type of artificial heart assist pump, the Novacor Left Ventricular Assist System (LVAS). Such measurements are critical in the effort to optimize hemodynamic conditions (e.g., velocities, shear rates, cell residence times) within the LVAS.
\end{abstract}

\subsection{INTRODUCTION}

In its recently released report to the National Heart, Lung and Blood Institute (NHLBI), the Institute of Medicine, through its Council on Health Care Technology, estimated that between 35,000 and 70,000 Americans annually require either permanent circulatory assist devices or cardiac transplantation [1]. For these patients, the therapy of choice remains cardiac transplantation. However, the donor heart supply is severely limited $(1,673$ cardiac transplants were performed in the United States in 1989) and is expected to remain so into the foreseeable future [2]. Thus, development of circulatory assist devices is critical to the survival of most of these heart-failure patients.

For the last 25 years, much of the work to develop circulatory assist devices involved pulsatile pumps that mimic the pumping action of the natural heart. Impressive progress has been made in solving the complex problems associated with the safe delivery of blood to the systemic circulation. In fact, several systems are now successfully used to support terminal cardiac patients who await transplantation $[3,4]$. One such device (Figure 1), the Novacor left ventricular assist system (NLVAS), has been used to support more than 100 heart-failure patients awaiting transplantation. Periods of support range from one day to 370 days. Since 1988 , the NLVAS has sustained 27 cardiac transplant candidates at the University of Pittsburgh's Presbyterian Hospital. Particularly impressive is the fact that all of the patients who received a donor heart (18/27) wnrn discharged from the hospital in good physical condition [5].
In spite of these encouraging clinical results, complex problems remain to be solved if these devices are to achieve widespread use. Problems of infection, bleeding, end-organ dysfunction, and thromboembolism have been reported by the various clinical centers utilizing these devices [6].

The motivation for this work is to optimize the hemodynamics of the LVAS and thus minimize the chance of undesirable activation of the hemostatic system in contact with biomaterial surfaces. This activation is likely a strong function of patient-dependent factors and the choice of biomaterials, but fluid-dynamic properties of the device are also important. Although the conditions that cause activation are not yet well understood, it is believed that high shear rates, areas of flow stasis and generation of strong recirculation zones are undesirable within any blood contacting device. By understanding the flow characteristics of the LVAS, this work will have immediate benefits for LVAS patients in that optimum modes of LVAS operation may be chosen as a function of their hemodynamic status. We have chosen to study the areas around the prothetic valves in the LVAS in which flow characteristics are likely to be most critical.

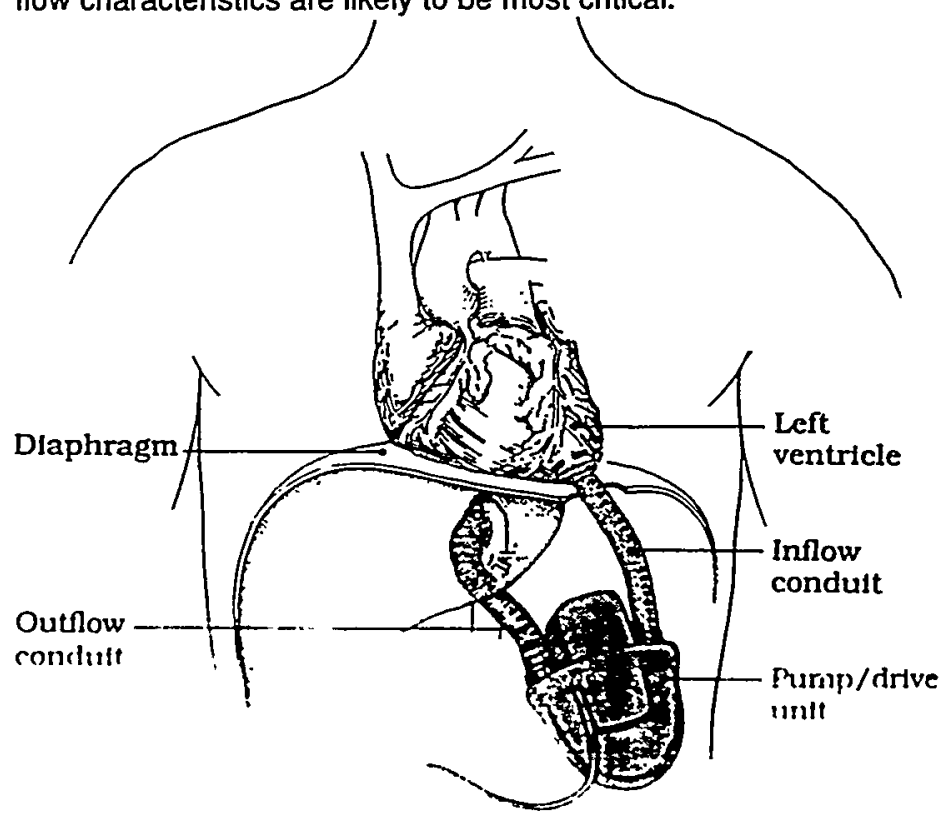

Figure 1. Anatomical configuration of the NLVAS. 


\subsection{APPROACH}

To achieve such desired blood flow behavior, it is helpful, if not essential, to use advanced flow diagnostic tools. A commonly used llow diagnostic tool is laser doppler velocimetry (LDV). LDV provides an instantaneous measurement of velocities at a single point in a flow field. LDV systems are also well-developed and commercially available.

In the present effort, we are using LDV; however, the primary measurements are done with a technique called fluorescent image tracking velocimetry or FITV. FITV is a particle imaging velocimetry technique that enables measurements very close to biomaterial surfaces.

With advances in computer imaging equipment and pulsed lasers, applications of particle image velocimetry are increasing rapidly. Another reason for the popularity of particle imaging velocimetry is its simplicity: afluid is seeded with particles that follow the fluid flow -- that is, neutrally-buoyant particles with low Stokes numbers and sizes much smaller than the length scales of the flow. A pulsed laser illuminates the seeded flow field at controlled intervals. The displacement of particles between laser pulses produces a velocity vector map of a flow field. From this, other important parameters, such as shear stress and particle residence time, are attainable.

Although the underlying concept of particle imaging velocimetry appears to be straightforward, considerable problems still remain. The main difficulties are in the acquisition of images with good signal-to-noise $(\mathrm{S} / \mathrm{N})$ ratios near flow boundaries and the digital analysis of images.

There are many variations of particle imaging velocimetry [7]. A double-pulse technique is known as particle image velocimetry or PIV. PIV produces a two-dimensional velocity map at an instant. The double-pulse technique has good spatial resolution but derives only the speed and orientation of velocity vectors - direction (sign) is unknown. A coded pulse sequence is one way to eliminate directional ambiguity. However, pulse coding often requires longer exposures and more pulses. This reduces spatial resolution due to the increased number and size of particle images. Yet another particle imaging velocimetry approach uses continuous pulsed illumination to produce Lagrangian trackings of particles through a flow field $[8,9]$.

Refractive/reflective lightscattering is adequate for mostparticle imaging applications. With enough illumination power, good signalto-noise (S/N) ratios between particle images and the background are achievable. Near solid flow boundaries, however, the S/N ratio may diminish to the point that particle images are undetectable. This is because scattering (refractive/reflective scattering will simply be referred to as scattering) from solid flow boundaries is usually much stronger than from small particles. Even if the refractive indices of the fluid and flow boundary are matched, impurities in the solid flow boundary can still generate strong scattering.

Use of fluorescent particles and color filtering is one way to enhance $S / N$ ratios near flow boundaries. Figure 2 illustrates the basic concept. A fluorescent-dyed particle is shown near a fluidsolid interface. A monochromatic light of wavelength $\lambda_{1}$ illuminates the scene.

When excited with light of an appropriate wavelength, the dye fluoresces or emits light. An important property of the fluorescent dye is its Stokes shift - the difference between excitation and emission wavelengths. Thus, the light from the particle shown in Figure 2 consists of both scattered light at the excitation wavelength $\left(\lambda_{1}\right)$ and fluoresced light at a different wavelength (mean fluorescent emission, $\lambda_{2}$ ). The light scattered by the flow boundary in Figure 2 is at the same wavelength as the excitation light.

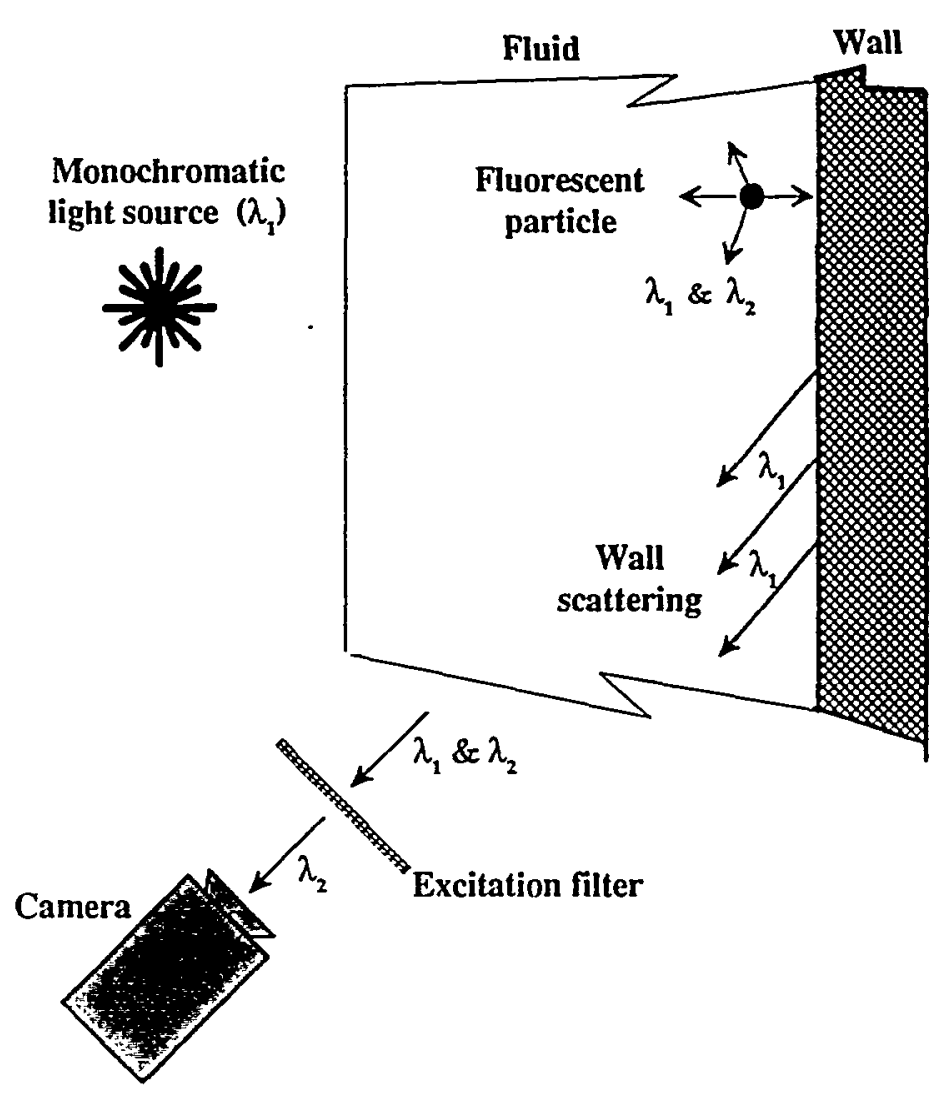

\section{Figure 2. Illustration of fluorescent particle and color filtering concept for near-wall particle imaging}

The $\mathrm{S} / \mathrm{N}$ ratio is increased dramatically by placing an excitation filter in front of the camera. The excitation filter occludes the light scattered by the flow boundary and the particle at $\lambda_{1}$ - the camera sees only the fluorescent light emitted by particles at $\lambda_{2}$. This has provided excellent $S / N$ ratios of particles close to biomaterial surfaces of the NLVAS.

\subsection{EXPERIMENTAL SETUP}

\subsection{FITV SYSTEM}

An FITV system consists of the following basic components: a pulsed excitation source, beam shaping optics, an excitation occlusion filter, an electronic camera with digital image acquisition system, and an image processing computer. Figure 3 shows the components of the USDOE's FITV system.

Excitation Light Sources The wavelength of the light source should be close to the peak excitation wavelength of the fluorescent dye. The excitation light source must produce pulsed light with accurate and controllable pulse timing. Continuous emission lasers with an acousto-optical modulator are ideal. Our experience indicates that at least 1 watt of optical power is necessary for FITV. See Adrian [7] and Shaffer et al. [8] for more information on pulsed light sources.

For this application, the excitation source is either an argon or a copper-vapor laser. The argon laser produces up to 5 watts of continuous light with the most powerful wavelengths $(\mathrm{nm})$ at 488 (blue) and 514.5 (green). Other less powerful lines are present at wavelengths from $350 \mathrm{~nm}$ to $507.1 \mathrm{~nm}$.

An electronically controlled acousto optic modulator (AOM) pulses the continuous beam of the argon laser The AOM transmission rise time limits the $A C)$ A pul-n rapabilities With a rise time of less than 50 ns. IIn AOM pulsos can iange fro"n continuous transmission to repetition rates over 1 1..1: I: and pulso durations less than a murro second. 

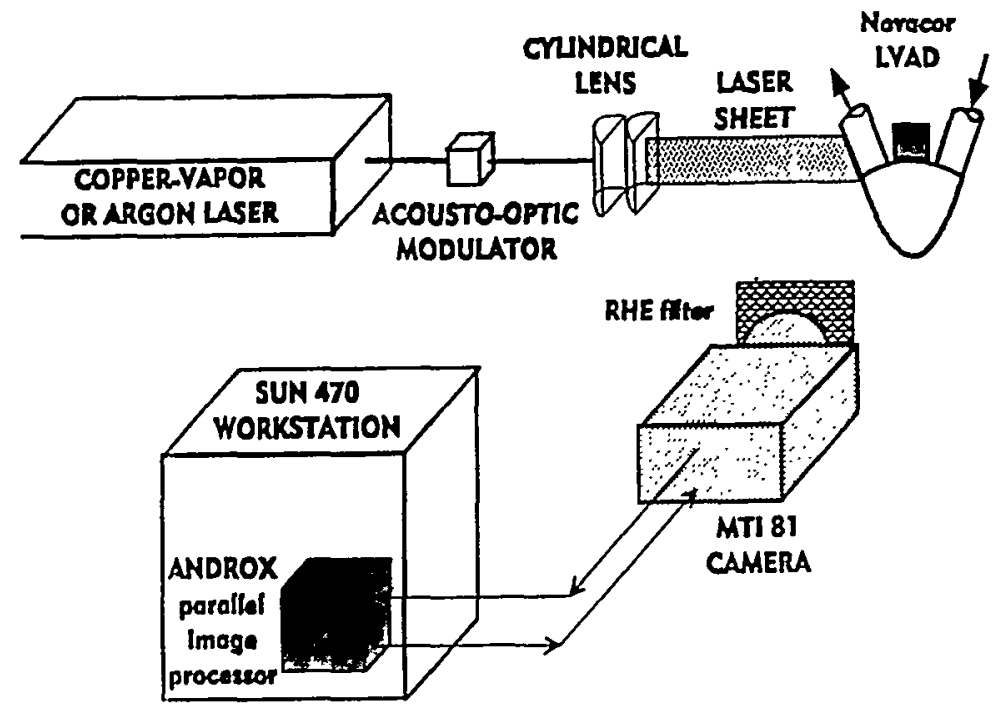

Figure 3. The USDOES FITV system used for this application.

The copper-vapor laser is a pulsed laser with pulse durations of $30 \mathrm{~ns}$ and repetition rates up to $20 \mathrm{KHz}$. Pulse energies range from 0.5 to $2 \mathrm{~m} . J$. it produces two primary wavelengths of 510.6 and 578.2 $\mathrm{nm}$ with a total average optical power of $10 \mathrm{~W}$. Only the $510.6 \mathrm{~nm}$ wavelength is used for this application. The copper-vapor laser is used only if the required pulse durations become short enough that the pulse energies from the argon laser drop well below $0.5 \mathrm{~mJ}$.

Beam shaping optics The beam shaping optics consist of a series of cylindrical lens $[9,10]$. They transform the circular cross section of the beam into a rectangular cross section with a large aspect ratio. This is commonly called a laser sheet.

Fluorescent-Dyed Particles Fluorescent particles are available from several commercial manufacturers. Some of the commercial manufacturers are Polyscience, [11], Duke Scientific [12], and Bangs laboratories [13]. Figure 4 shows the excitation and emission characteristics of a commercial fluorescent particle [12]. The dye in this particle is suitable for excitation with the green wavelengths of argon $(514.5 \mathrm{~nm})$ and copper-vapor $(510.6 \mathrm{~nm})$ lasers. Other fluorescent-dyed particles are available for excitation with lasers of different wavelengths.

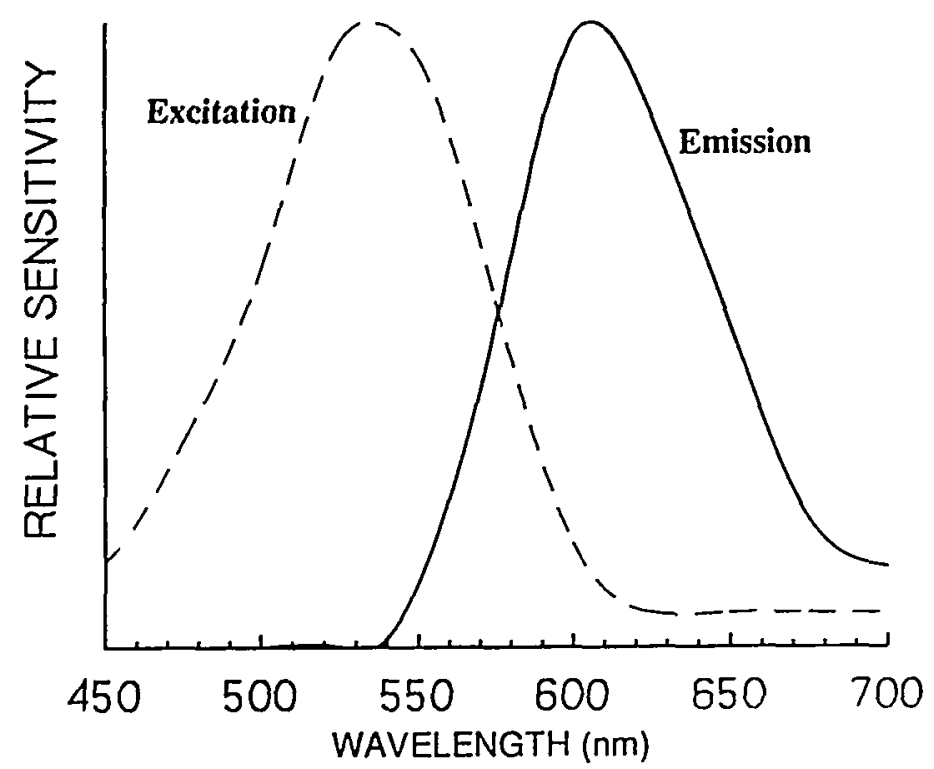

Figure 4. Excitation and emission spectra of a commercial fluorescent-dyed particle (Duke Sclentiflc "red" fluorescent particles [12]).
Excitation Filters The purpose of the excitation filter is tc occlude the excitation wavelength(s) and pass the fluorescen' wavelengths. With monochromatic excitation, the ideal filter wil block only a single wavelength. Three types of filters approact monochromatic occlusion: thin-film dielectric interference filters Raman holographic edge (RHE) filters, and colloidal Bragg diffrac. tion filters. The mean occlusion characteristics of the interference and RHE filters are practically the same [14]. The transmission characteristics of an RHE [15] and a colloidal filter [16] are shown in Figure 5.

Since the Stokes shiftis significant $(>20 \mathrm{~nm})$ formany fluorescent dyes, an edge filter can possibly be used. Edge filters are much less expensive than the notch filters. Figure 5 also shows the transmission curve of an inexpensive edge filter [17].

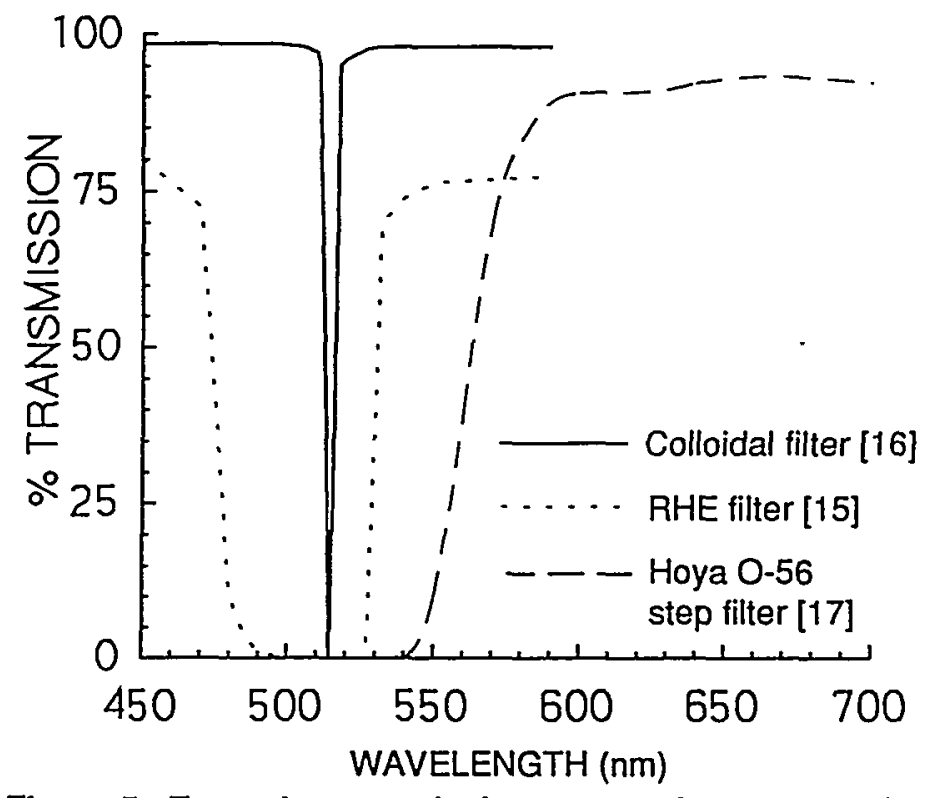

Figure 5. Example transmission spectra for notch and step filters.

Image acquisition system The camera is a MTI Model 81 tube camera. The camera scanning parameters are externally controlled through an ANDROX programmable video controller. An ANDROX analog-to-digital converter (ADC) digitizes the analog output of the MTI 81. With this setup, image resolutions from $512 \times 512$ pixels to $2048 \times 1800$ pixels are attained. The grey-level resolution of each pixel is 8 bits. The frame rate is variable from 10 frames per second ( $2048 \times 1800$ pixel resolution) to 100 frames per second $(512 \times 512$ pixel resolution).

Image processing computersystem Processing and analysis of FITV images are done on a SUN 470 workstation equipped with an ANDROX parallel image processing subsystem. The ANDROX system accelerates many image processing functions by a factor of 50 or more over the SUN 470 CPU.

Over the past few years development of custom software to analyze PITV and FITV data has been underway at the DOE. The interested reader is referred references [18] and [19] for more information on this software.

\subsection{CARDIAC SIMULATION FLOW LOOP}

Figure 1 shows the Novacor LVAS in one of two anatomical configurations. The LVAS is placed extraperitoneally within the abdomnn. with the inflow conduit connected to the left ventricular apex lin nutfinw condist may be anastomosed to mithor the

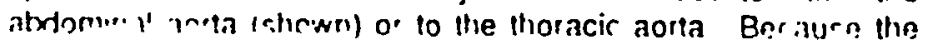

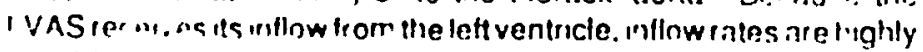

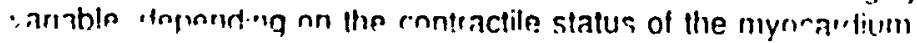


In the immediate post-operative period, the contractility of the diseased myocardium is additionally depressed by anaesthetic agents. Under these conditions, the ventricle functions almost as a passive conduit and therefore the LVAS inflow is relatively constant. However, because the LVAS allows the myocardium to deliver flow at a greatly reduced afterload, myocardial contractile function may recover and increase beyond pre-implant values within a few days. The ventricle then acts as a "priming pump" for the LVAS, and the inflow to the LVAS becomes markedly pulsatile with peak flow rates of as much as four to five times greater than the immediate post-operative values.

For this study it is essential to acquire the FITV images under representative patient conditions, including varying degrees of myocardial contractility. For this purpose, an active mock loop has been designed (Figure 6). Inflow to the LVAS is provided by a servocontrolled piston pump which is able to produce an arbitrary flow waveform based on a voltage command. Using a programmable waveform generator, it is possible to generate LVAS inflow waveforms that accurately mimic inflows monitored from patients in the operatinn room or intensive-care unit at the University of Pittsburgh [20].

Flow patterns in the LVAS are also a function of the afterload presented to it. The LVAS afterload in this mock loop uses a calibrated compliance to simulate the systemic vascular compliance and a pneumatic pressure regulator to maintain the mean arterial pressure within physiological values independent of flow, just as occurs in the body via the baroreceptor reflex. The mockloop is instrumented with an ultrasonic transit-time flowmeter and clinical pressure transducers.

An NLVAS was manufactured from transparent materials to provide optical access for FITV. A transparent blood analog fluid which has a viscosity close to that of blood ( $4 \mathrm{cps}$ ) was also used. The blood analog fluid consists of a solution of $42 \%$ wt. aqueous spectrophotometric-grade glycerin.

The blood analog fluid was seeded with "red" fluorescent particles manufactured by Duke Scientific [12]. The particles consist of polystyrene latex and a proprietary mixture of fluorescent dyes. They are neutrally buoyant and their size is $30 \pm 2$ micron.

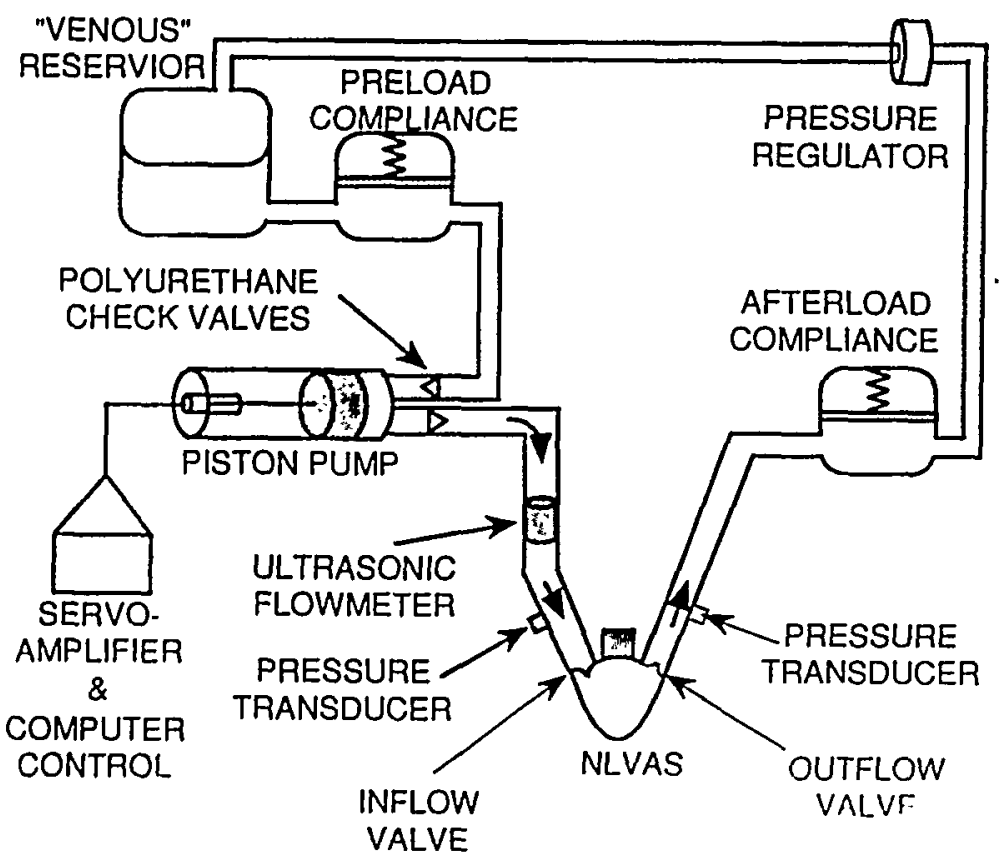

Figure 6. Cardiac simulation flow loop.

\subsection{RESULTS}

\subsection{PERFORMANCE OF EXCITATION FILTERS}

Several filters were tested for the present application. These include an RHE filter [15] and several inexpensive step filters. Rather than attempting an independent measurement of optical density, the performance parameter ( $S / N$ ratio) pertinent to this application was measured under typical operating conditions.

The test consisted of measuring the $S / N$ ratios produced with our FITV system for a fixed, representative scene. The scene was a pericardial trileaflet valve in its transparent housing filled with blood analog fluid. The housing, pericardial valve, and blood analog fluid are the same as used in actual flow measurements. The only experimental variable was the type of excitation filter placed in front of the camera lens.

Figure 7 shows a pericardial valve used in the NLVAS. The valve is constructed of bovine heart tissue formed into three flexible leaflets that open and close to restrict flow to one direction. Figure 8 shows the pericardial valve in its transparent housing filled with blood analog fluid.

The valve leaflet material was found to have mild fluorescent properties. This is undesirable since it increases the background level. Dying the valve with a black clothing dye practically eliminates the valve's fluorescence.

In Figure 9, the same scene as in Figure 8 is illuminated with 1 $W / \mathrm{cm}^{2}$ of $510.6 \mathrm{~nm}$ light from a copper-vaporlaser. Figure 10 shows exactly the same scene as Figure 9 but with an RHE filter in front of the camera. Fluorescent particles are now noticeable. Some of the particles are suspended in the fluid while others are adhering to the surface of the pericardial valve or the walls of the transparent housing. The particles tended to move slowly due to radiative heating of the stagnant fluid by the laser light.

In Figure 10, the room lights are on so the valve and transparent housing are still visible. In Figure 11, the room lights are turned off so only the light emitted by the fluorescentparticles is seen. Note that the fluorescent particles were also present in Figures $8-10$.

As Figure 11 illustrates, the S/N ratio is excellent - even for particles adhering to the valve surface and housing walls. Both the RHE filter and Hoya O-56 filter produced S/N ratios exceeding the maximum level detectable with the FITV system used for this application.

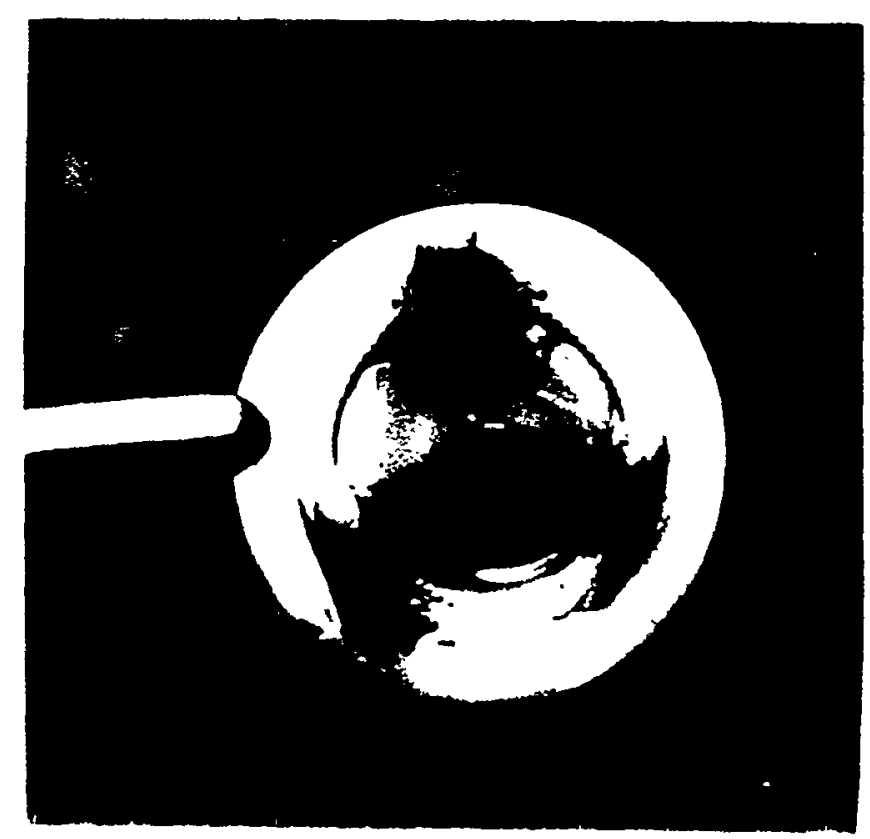

Figure it the pericardial trileaflet valve used in thr NIVAD. 


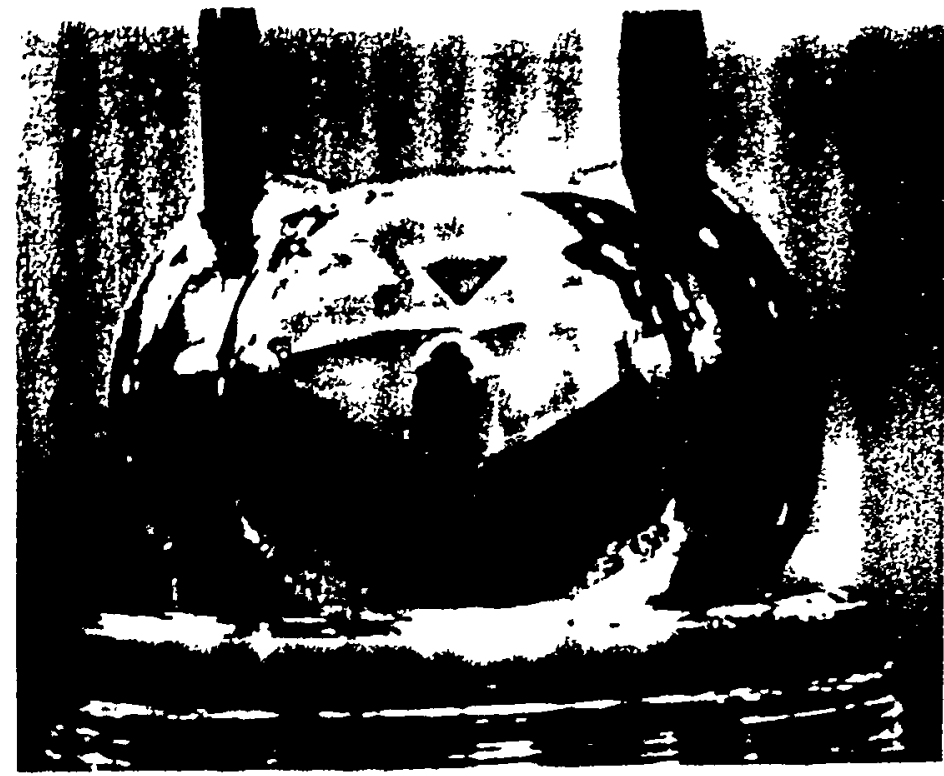

Figure 8. A pericardial valve in a transparent housing used for FITV measurements.

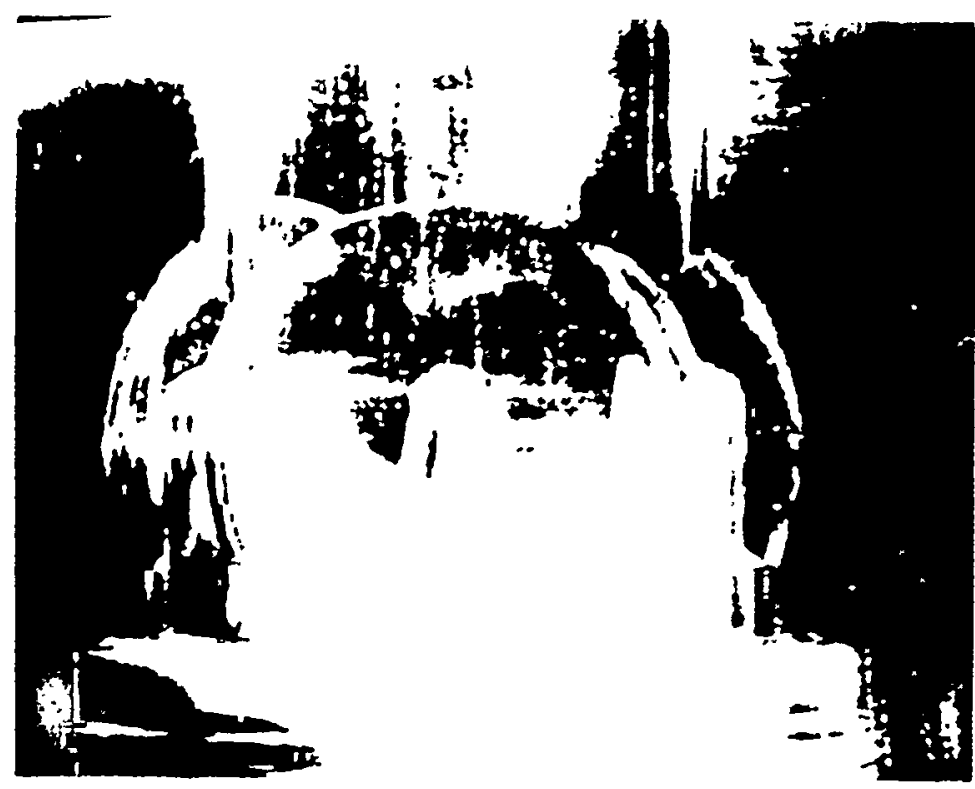

Figure 9. A copper-vapor laser illuminates the pericardlal valve with $510.6 \mathrm{~nm}$ light.

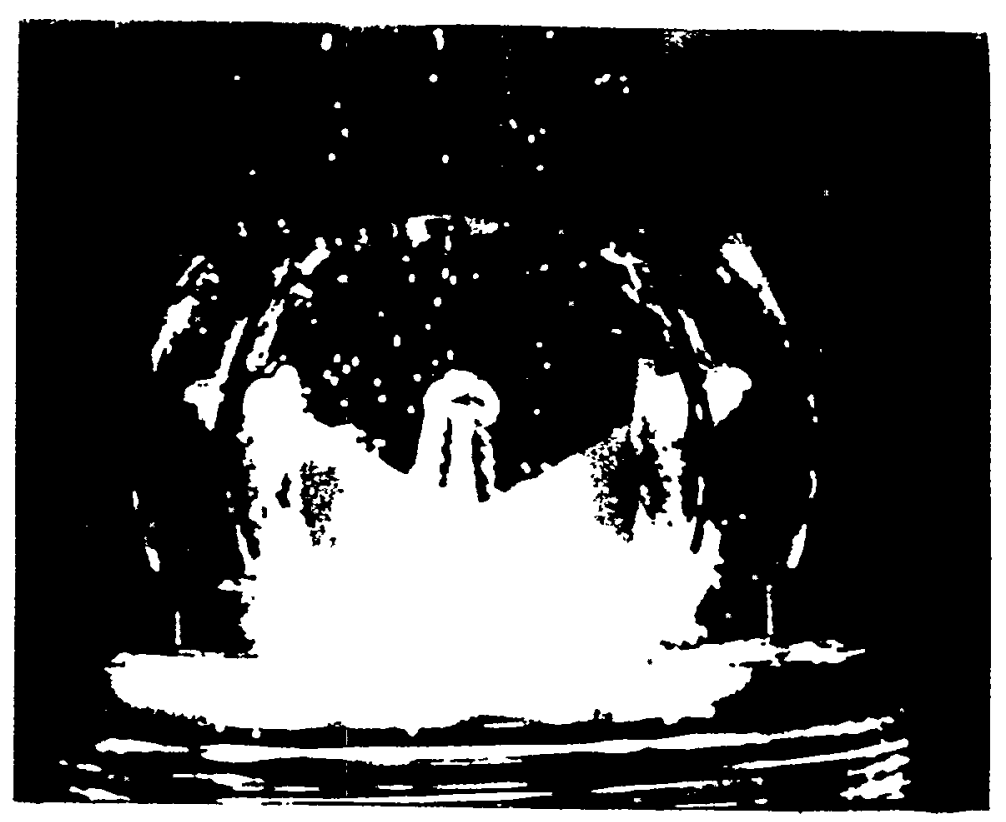

Figure 10. Same scene as in Figure 9, except an RHE filter is placed in front of the camera. Room lights are on so that valve and housing are visible.

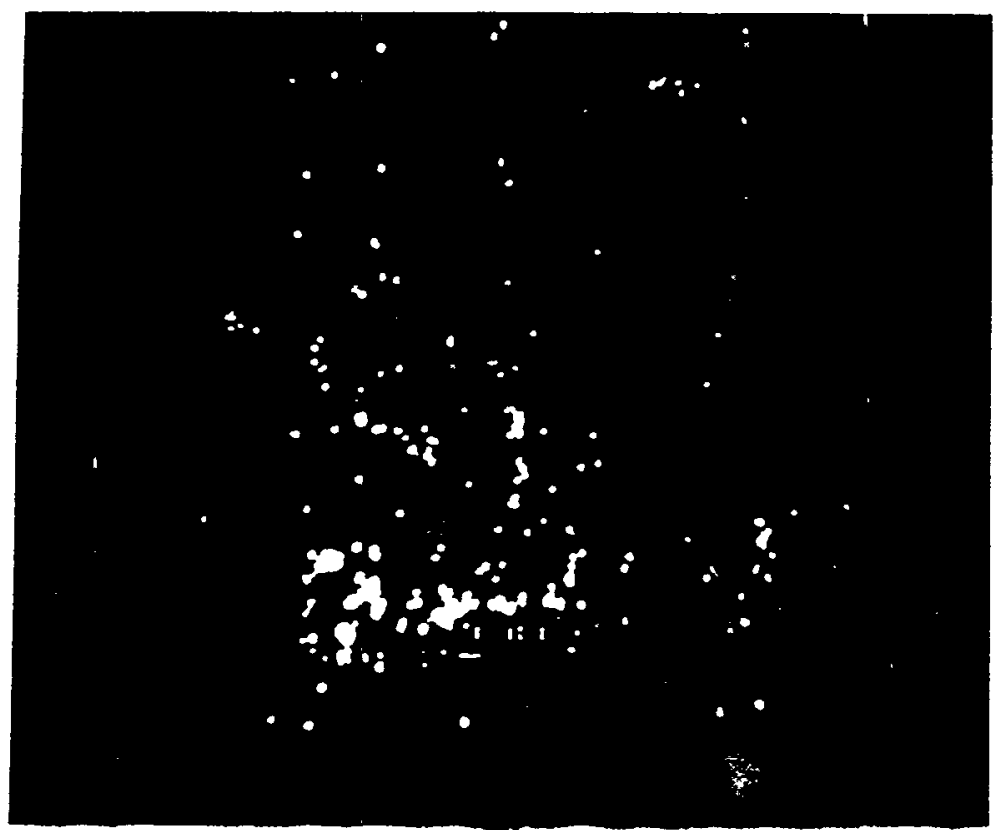

Figure 11. Same scene as Figure 10 but with room lights turned off.

\subsection{EXAMPLE FITV MEASUREMENTS}

The flow conditions for FITV measurements simulated the full range of clinical conditions observed for cardiac transplant patients at the University of Pittsburgh: pump rates ranged from 60 to 120 beats/minute with fill volumes ranging from 25 to $60 \mathrm{cc}$ [20].

During a cardiac cycle, the FITV system acquires six images at fixed time separations. For example, if the cardiac cycle duration were $600 \mathrm{~ms}$, six measurements are made at $100 \mathrm{~ms}$ separations. After digitizing six images into video-RAM, the images are compressed and stored on the SUN 470 hard disk. The acquisition and storage of six FITV images takes about 20 seconds. For a specific experimental condition, data is acquired for at least 100 cardiac cycles. 
1 gure 12 shows the location of one of the inflow pericardial vali: :alps at $100 \mathrm{~ms}$ intervals through a $600 \mathrm{~ms}$ cardiac cycle. The images - Figure 12 are with constant room illumination and $50 \mathrm{~ms}$ exposure umes. For the actual FITV measurements the room lights are off. The AOM delivers a sequence of pulses during each frame. For these initial measurements. the pulse sequence consists of four pulses at a fixed frequency. Software is under development at thr DOF that will handle corled pulse sequenres.

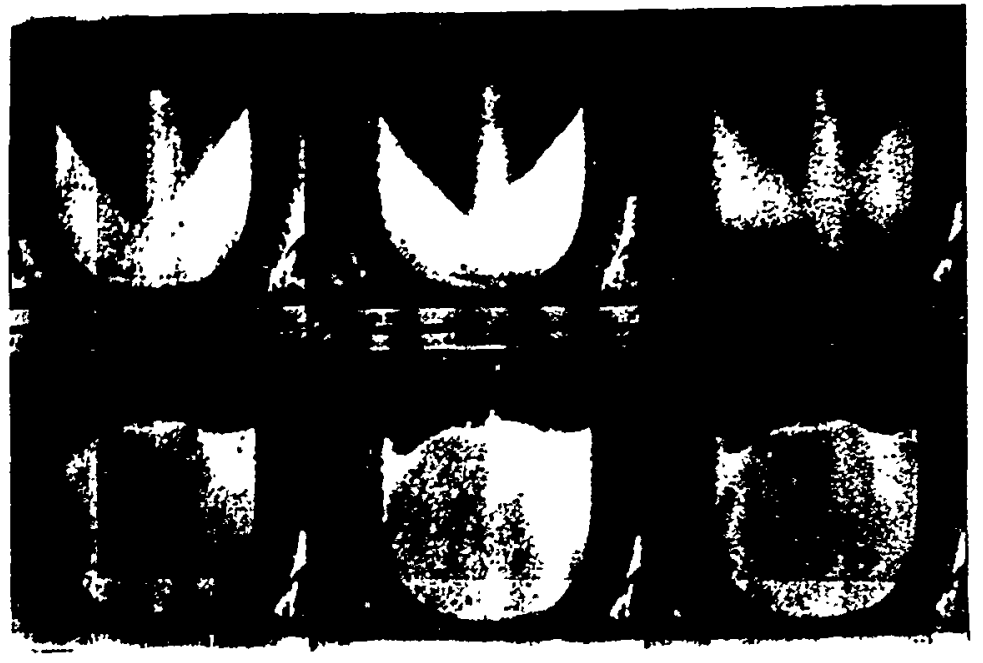

rigure 12. Location of the pericardial valve flaps (inflow)

Figure $13 a$ and $13 b$ show two examples of typical FITV images. Higure 13a is taken at the beginning of the systole (first frame of Figure 12); the flow velocities are high because valve flaps are in inolion (closing). Figure $13 \mathrm{~b}$ is taken near mid-diastole when the valve flaps are not moving (fully open) and the velocities are much lower. Consequently, to maintain reasonable spacings between consecutive particle images, the laser pulse frequency is varied from trame-to-frame throughout the cardiac cycle. For example, the puls fro quency in Figure $13 \mathrm{a}$ is $1 \mathrm{KHz}$ and in Figure $13 \mathrm{~b}$ it is $222 \mathrm{~Hz}$.

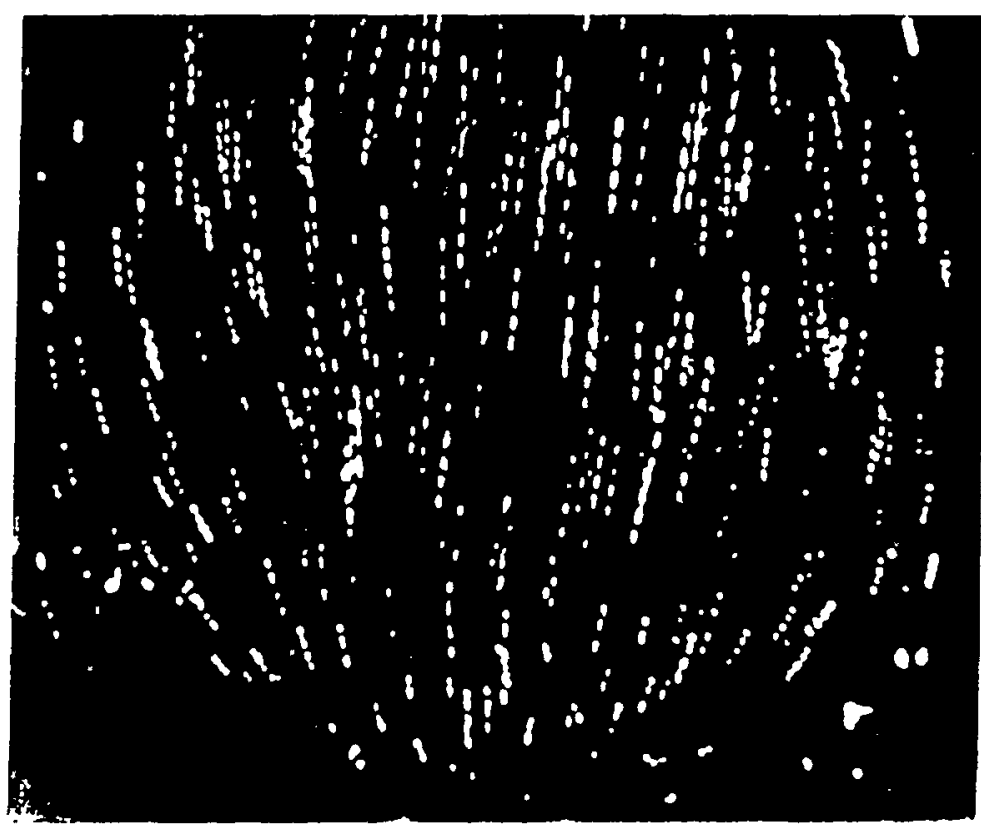

Fi yure 13a. Example riTV imagn laken 10 a's afle tho slall of systole.

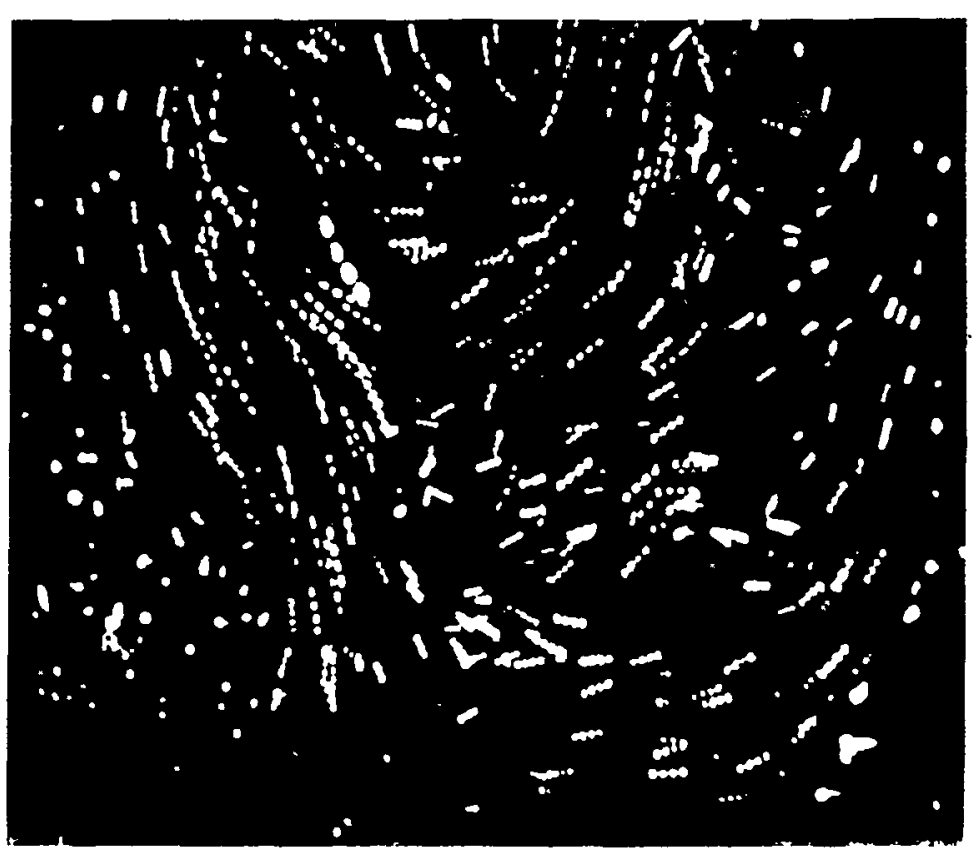

Figure 13b. Fxample FITV image near middlo of iaistole.

Figures $14 \mathrm{a}$ and $14 \mathrm{~b}$ show initial attempts to visualize the FITV data extracted from Figure 13b. Figure 14a shows a contour map of velocily magnitude (speed). The brighter areas represent higher speeds and the darker areas lower speeds. Figure 14b shows a velocity vector map derived from Figure 13b. Arrowheads are not shown on the velocity vectors since, as explained earlier, uncoded pulse trains do not determine velocity direction (sign). An inversedistance domain interpolation of the randomly located data of Figure $13 \mathrm{~b}$ produces a uniform grid of property values. This was necessary to produce Figures $14 \mathrm{a}$ and $14 \mathrm{~b}$. Figures $14 \mathrm{a}$ and $14 \mathrm{~b}$ are shown only as an example of the type of results produced by FITV masuremints.

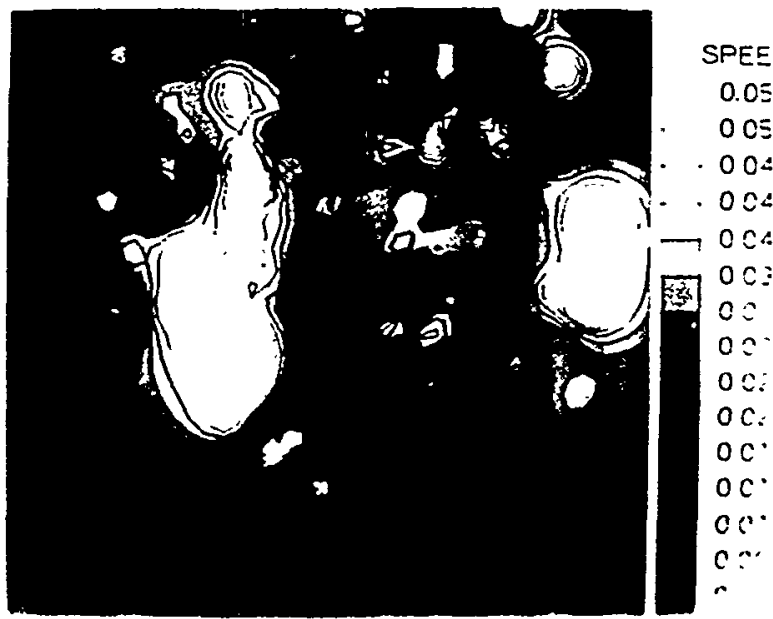

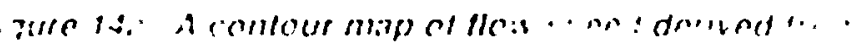

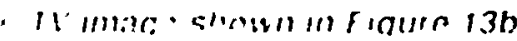




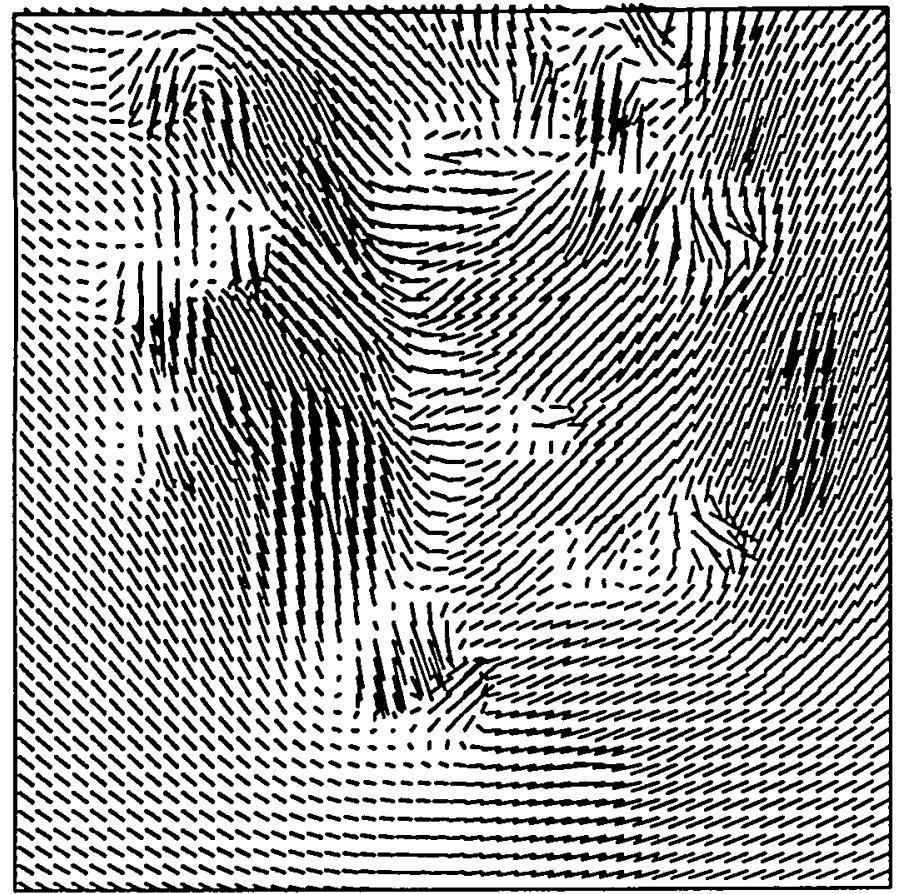

Figure 14b. A velocity vector map derived from FITV Image shown in Figure 13b.
DISCLAIMER

Reference herein to any specific commercial product, process, or service by trade name, manufacturer, or otherwise, does not necessarily constitute or imply its endorsement, recommendation, or favoring by the United States Government or any agency thereof.

\section{REFERENCES}

[1] The Artificial Heart: Prototypes. Policies and Patients. edited by Hogness, J.R. and VanAntwerp, M., National Academy Press, Washington, DC, 1991.

[2] "Heart transplants: concerns about cost, access, and availability of donor organs," U.S. General Accounting Office Report to the Chairman, Subcommittee on Health, Committee on Ways and Means, House of Representatives, May, 1989.

[3] Poirier, V.L., "The Heartmate Cardiac Assist System," Cardiovascular Science \& Technology: Basic and Applied.ll, pp. 351, 1990-91.

[4] Portner, P.M., Oyer, P.E., Pennington, D.G., et al., "Implantable Electrical Left Ventricular Systems: Bridge to Transplantation and to the Future," Annals of Thoracic Surgery, Vol. 47, pp. 142-150, 1989. [5] Kormos, R.L., Borovetz, H.S., Armitage, J.M. et al., "Evolving Experience with Mechanical Circulatory Support," Annals of Surgenv, Vol, 214, pp. 471-477, 1991.

[6] Didisheim, P., Olsen, D.B., Farrar, D.J. et al., "Infections and thromboembolism with implantable cardiovascular devices," Transactions of the American Society for Artificial Internal Organs, Vol. 35, pp. 54-70, 1989.

[7] Adrian, R.J., "Multi-point Optical Measurement of Simultaneous Vectors in Unsteady Flow - a Review," Int.J. Heat \& Fluid Flow, Vol. 7 , No. 2, June 1986.

[8] Shaffer, F.D., Ekmann, J.M, and Ramer, E.R., "Development of Pulsed Laser Velocimetry Systems with Photoelectric Image Sensors," AIAA Paper 88-3777, AIAA/ASME/ASCE/SIAM/APS First National Fluid Dynamics Congress, pp. 1944-1952, Cincinnati, Ohio, July 1988.

[9] Shaffer, F.D. and Ramer, E.R., "Pulsed Laser Imaging of ParticleWall Collisions," Int. Conf. on Mechanics of Two-Phase Flow, Taipei, Taiwan, June 1989.

[10] Diemunsh, G. and Prenel, J.P., "A Compact Light Sheet Generator for Flow Visualization," Opt. Lasers, Vol. 19, No. 3, June 1987.

[11] Polyscience, Inc., Warrington, PA.

[12] Duke Scientific Corporation, Palo Alto, CA.

[13] Bangs Laboratories, Inc., Carnel, IN.

[14] Rich, C. and Cook, D., "Lippman Volume Holographic Filters for Rayleigh Line Rejection in Raman Spectroscopy," Physical Optics Corporation, Internal Report.

[15] Physical Optics Corporation, Torrance, CA.

[16] Flaugh, P.L., O'Donnel, S.E., and Asher, S.A., "Development of a New Optical Wavelength Rejection Filter: Demonstration of Its Utility in Raman Spectroscopy," Applied Spectroscopy, Vol. 38, No. $6,1984$.

[17] Hoya Optics, Inc., Freemont, CA.

[18] Ramer, E.R. and Shaffer, F.D., "Automated Analysis of MultiplePulse Particle Image Velocimetry Data," accepted for publication in the Journal of Applied Optics, 1991.

[19] Srinivasan, R., Singh, R., and Shaffer, F.D., "Image Analysis Techniques for Particle Tracking Velocimetry," submitted to the Int. Conf. on Pattern Recognition, Copenhagen, Denmark, 1992.

[20] Kormos, R.L., Borovetz, H.S., Pristas, J.M., et al., "LVAS pump performance following initiation of left ventricular assistance," Iransactions of the American Society for Artificial Internal Qrgans. Vol. 36. pn Mi03 Mi705 1990. 